ELKOMIIKA: Jurnal Teknik Energi Elektrik, Teknik Telekomunikasi, \& Teknik Elektronika.

\title{
Perbandingan Kinerja Pengontrol PID menggunakan Antarmuka OPC pada PLC dan MATLAB untuk Sistem Pasteurisasi Susu
}

\author{
YULIAN ZETTA MAULANA, HERRYAWAN PUJIHARSONO \\ Institut Teknologi Telkom Purwokerto, Indonesia \\ Email:yulian@ittelkom-pwt.ac.id
}

Received 6 Desember 2020| Revised 5 Januari 2021| Accepted 2 Februari 2021

\begin{abstract}
ABSTRAK
PLC digunakan pada pengontrolan suhu pada pasteurisasi susu. Di sisi lain, MATLAB memiliki variasi pengontrol yang lebih luas dan dapat terhubung ke sistem Pasteurisasi Susu menggunakan OPC. Namun, penggunaan OPC dikhawatirkan akan menurunkan kinerja sistem karena waktu tunda dan waktu sampling. Penelitian ini bertujuan untuk membandingkan kinerja pengontrolan PID pada sistem pasteurisasi susu dari MATLAB dan PLC dengan memperhatikan pengaruh antarmuka OPC. Pada penelitian ini, kinerja peralihan sistem diukur dengan pengontrol yang berbeda, menggunakan metode penalaan yang berbeda dan berasal dari PLC dan MATLAB. Hasil penelitian menunjukkan bahwa penggunaan OPC tidak memberikan efek negatif pada kinerja sistem. Nilai rata-rata MSE setelah keadaan stabil pada pengontrol PI adalah 70,66 sedangkan pada pengontrol PID 1,16. Nilai MSE Pengontrol PID dengan Penalaan Cohen Coon adalah 0,356. Dapat disimpulkan bahwa pemilihan piranti pengontrol lebih memiliki efek signifikan terhadap kinerja dibandingkan dengan penggunaan OPC.
\end{abstract}

Kata kunci: Pasteurisasi, Cohen Coon, PLC, MATLAB, OPC

\begin{abstract}
PLC can be used to control temperature in milk pasteurization process. MATLAB has more usable Controllers that can be used in milk pasteurization process through OPC. The concern is that the use of OPC will reduce system performance due to delay and sampling time. This study aims to compare the performance of PID control in the milk pasteurization system usingMATLAB and PLC as controllersregarding the effect of using OPC interfaces. In this research, the transient response performance of the system was measured using different type of controllers, twhich use different tuning methods based on PLC and MATLAB. The results showed that the use of OPC did not have a negative effect on system performance. The MSE average in a steady condition for PI controller is 70,66, and for PID controller is 1,16. MSE result using Cohen Coon controller is 0,356. So it can be concluded that the choice of the control device has a more significant effect on performance than with the use of OPC.
\end{abstract}

Keywords: Pasteurization, Cohen Coon, PLC, MATLAB, OPC 
Perbandingan Kinerja Pengontrol PID menggunakan Antarmuka OPC pada PLC dan MATLAB untuk

Sistem Pasteurisasi Susu

\section{PENDAHULUAN}

Proses pengaturan suhu pada susu pasteurisasi dapat dikategorikan pada pengaturan kritis karena pemanasan pada suhu yang terlalu tinggi akan merusak kualitas susu, sementara pemanasan pada suhu yang terlalu rendah tidak akan mampu membunuh bakteri yang ada pada susu sehingga dibutuhkan pengontrol pasteurisasi agar susu bisa dipanaskan dengan suhu yang sesuai dalam rentang waktu tertentu. Pemanasan untuk jenis HTST (High Temperature Short Time Pasteurization) dilakukan sampai suhu susu adalah $72{ }^{\circ} \mathrm{C}$ selama 15 detik (Watts, 2016). Dengan kata lain, susu harus berada pada suhu $72{ }^{\circ} \mathrm{C}$ selama 15 detik agar bisa efektif membunuh bakteri, walaupun bisa jadi proses pasteurisasi susu untuk mencapai suhu $72{ }^{\circ} \mathrm{C}$ membutuhkan waktu yang lama. Untuk mencapai tujuan tersebut, diharapkan pengontrolan yang dilakukan mampu menghasilkan nilai sesuai set point tanpa ada overshoot yang besar dan dalam rentang waktu yang kecil untuk meminimalkan biaya.

Suatu proses pengontrolan sedapat mungkin menghasilkan kinerja sistem yang baik. Ada berbagai macam metode pengontrolan, di mana penggunaannya tergantung dari sistem yang dikontrol. Selain metode pengontrolan yang berbeda, pengontrolan juga bisa dilakukan menggunakan perangkat keras yang berbeda. Perangkat keras yang berbeda ini bisa jadi menghasilkan kinerja pengontrolan yang berbeda walaupun jenis pengontrol dan metode yang digunakan adalah sama.

Salah satu jenis perangkat pengontrol yang sering digunakan di dunia industri adalah PLC (Programmable Logic Controller). Pengontrol yang biasa digunakan pada PLC adalah pengontrol PID (Proportional, Integral, Derivative). Namun, jenis-jenis pengontrol lain seperti MPC (Model Predictive Control), pengontrol menggunakan logika Fuzzy dan pengontrol adaptif jarang digunakan pada PLC karena karakteristik PLC yang menggunakan pemrograman tangga/ ladder diagram. Padahal, penggunaan PLC relatif luas di dunia industri dan harganya tidak semahal pengontrol lainnya. Pemrograman untuk pengontrol advanced cukup sulit dilakukan menggunakan ladder diagram sehingga pengontrol jenis advanced pada umumnya dibuat di perangkat lunak lain, contohnya MATLAB, yang kemudian diintegrasikan menggunakan OPC (Object Linked Embedded for Process Control).

Ada dua permasalahan yang diteliti. Permasalahan pertama adalah penggunaan OPC yang dikhawatirkan akan menurunkan kinerja sistem karena proses integrasi akan menimbulkan waktu tunda dan proses penyamplingan yang akan mengubah parameter sistem. Oleh karena itu, penelitian ini dilakukan untuk mengetahui perbandingan kinerja sistem yang menggunakan PLC yang terintegrasi dengan OPC, MATLAB yang terintegrasi dengan OPC, dan yang menggunakan MATLAB saja. Permasalahan kedua adalah pengujian efektivitas penggunaan MATLAB sebagai pengontrol apabila dibandingkan dengan PLC. Jenis pengontrol yang digunakan adalah PID dan PI dengan Metode Penalaan Ziegler Nichols dan Cohen Coon.

Penelitian tentang pengontrolan pada proses pasteurisasi sudah sering dilakukan. Salah satunya adalah penelitian tentang perbandingan antara pengontrol advanced (MPC) dengan PID pada sistem pasteurisasi yang menunjukkan bahwa metode MPC menghasilkan kinerja yang lebih baik (Alamirew, dkk, 2017). Namun, perangkat yang digunakan bukanlah PLC. Penelitian lain yang menggunakan PLC untuk pengontrolan proses pasteurisasi adalah Pengontrolan Autotuning PID yang menggunakan PLC jenis Siemens (Suthar, dkk, 2015). Namun, penelitian ini belum mengintegrasikan PLC dengan OPC.

MATLAB dapat digunakan untuk melakukan proses pengontrolan dengan variasi pengontrol yang beraneka ragam dan lebih luas. Antarmuka antara MATLAB dengan plant sistem dapat dilakukan dengan menggunakan OPC. Salah satu jenis OPC yang biasa digunakan adalah 
KEPServerEX. Kendala utama dari aplikasi OPC adalah waktu tunda dan proses penyamplingan yang timbul karena penggunaan OPC ini. Penelitian sebelumnya menunjukkan bahwa integrasi OPC dan PLC untuk pengaturan kontrol sistem menunjukkan hasil yang handal (Kafuko \& Wanyama, 2015) (Wanyama \& Singh, 2013). OPC mampu mengintegrasikan sistem yang dikontrol menggunakan PLC yang berbeda sehingga penggunaan OPC pada PLC diharapkan tidak mengurangi kinerja pengontrol (Pranowo, dkk, 2020). Penelitian yang menggabungkan OPC, pengontrol PID, MATLAB, dan PLC pada sistem berhasil memprediksi model PID untuk diterapkan pada sistem massa pegas (Sartika, dkk, 2019). OPC juga mampu mengintegrasikan pengontrol pada MATLAB dengan sistem (Cao, dkk, 2015) (Valarezo, dkk, 2016).

Benang merah dari penelitian-penelitian di atas menyimpulkan bahwa sistem yang tepat untuk diaplikasikan menggunakan pengontrol yang terkoneksi dengan OPC tersebut adalah pengontrol yang memiliki respon lambat. Karena waktu tunda tidak akan memberikan efek yang signifikan pada sistem yang memang memiliki waktu tunda besar. Dengan demikian, integrasi OPC PLC dan MATLAB cocok diterapkan pada sistem pasteurisasi susu. Namun demikian, perlu ditelaah lebih lanjut terkait dengan efektivitas kinerja pengontrol yang menggunakan MATLAB dengan antarmuka OPC jika dibandingkan dengan pengontrol yang menggunakan PLC yang juga menggunakan OPC pada sistem pasteurisasi susu.

Dalam penelitian ini, pengontrol PID yang berasal dari PLC dan yang berasal dari MATLAB dibandingkan untuk sistem pasteurisasi susu di mana pengontrol dari MATLAB dibuat skenario ada yang terhubung dengan OPC ke server dan ada yang tidak terhubung.

\section{METODE PENELITIAN}

\subsection{Identifikasi Sistem}

Penelitian ini dilakukan dengan melakukan simulasi berdasarkan fungsi alih sistem pasteurisasi susu. Fungsi alih tersebut disimulasikan menggunakan MATLAB. Plant pasteurisasi yang digunakan adalah mini plant armfield dan gambarnya bisa dilihat pada Gambar 1.

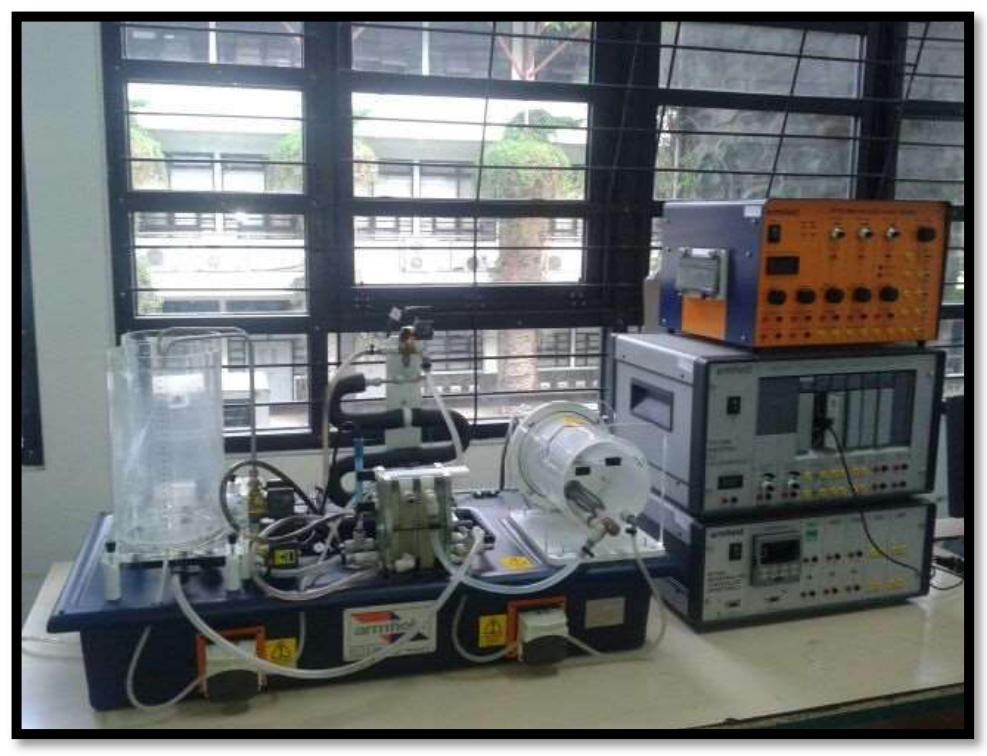

Gambar 1. Mini Plant Pasteurisasi Susu 
Mini plant tersebut menggunakan alat penukar kalor untuk memanaskan susu pasteurisasi. Persamaan (1) dan (2) di bawah ini menyatakan hubungan ideal antara pertukaran kalor fluida panas dengan fluida produk (dalam hal ini adalah air susu pasteurisasi).

$$
\begin{aligned}
& \dot{m}_{\text {in. }} \cdot c \cdot \Delta T_{1}+\dot{m}_{h} \cdot c \cdot \Delta T_{2}+Q=m_{i n} \cdot c \cdot \frac{d T_{1}}{d t} \\
& \dot{m}_{\text {in }} \cdot c \cdot \Delta T_{1}+\dot{m}_{h} \cdot c \cdot \Delta T_{2}+Q=m_{i n} \cdot c \cdot \frac{d T_{2}}{d t}
\end{aligned}
$$

Di mana $\dot{m}_{\text {in }}$ menyatakan laju aliran massa dari fluida dingin, $c$ menyatakan kalor jenis dari fluida produk, $\Delta T_{1}$ menyatakan perbedaan temperatur keluaran fluida dingin atau fluida produk dari alat penukar kalor dengan temperatur masukan fluida dingin pada alat penukar kalor, $Q$ menyatakan besar daya pemanas yang diberikan, $\dot{m}_{h}$ menyatakan laju aliran massa fluida panas, dan $\Delta T_{2}$ menyatakan perbedaan antara temperatur fluida panas yang keluar alat penukar kalor dengan temperatur panas yang masuk ke alat penukar kalor. Model fungsi alih tersebut disimulasikan menggunakan pendekatan first order with time delay ( 2018).

Penentuan fungsi alih sistem dilakukan setelah memastikan kelinieran dari sistem. Sebelum dilakukan pendekatan matematis, diperlukan identifikasi statis dari sistem untuk menentukan kelinieran sistem. Diagram sistem pasteurisasi dapat dilihat pada Gambar 2. Sistem dioperasikan secara manual kemudian diberi input daya pemanas sebesar 15\%, 25\%, 35\%, $45 \%$, dan $65 \%$ yang akan menghasilkan panas yang terukur pada T2. Aliran air pada T2 akan memanaskan susu, di mana susu yang dipanaskan akan terukur pada T4. Untuk menjaga agar susu tidak terlalu panas, maka dilakukan proses pendinginan melalui proses penukaran kalor lagi. Produk susu yang dihasilkan diukur pada T3. Dengan menggunakan daya outputpemanas yang berbeda-beda, diperoleh nilai yang linier pada output-nya. Setelah sistem dianggap linier, maka pemodelan fungsi alih menggunakan first order with time delay bisa dilakukan. Fungsi alih mengambil masukan berupa daya pemanas dan output T3. Fungsi alih ini digunakan dalam bentuk persamaan yang disimulasikan pada MATLAB.

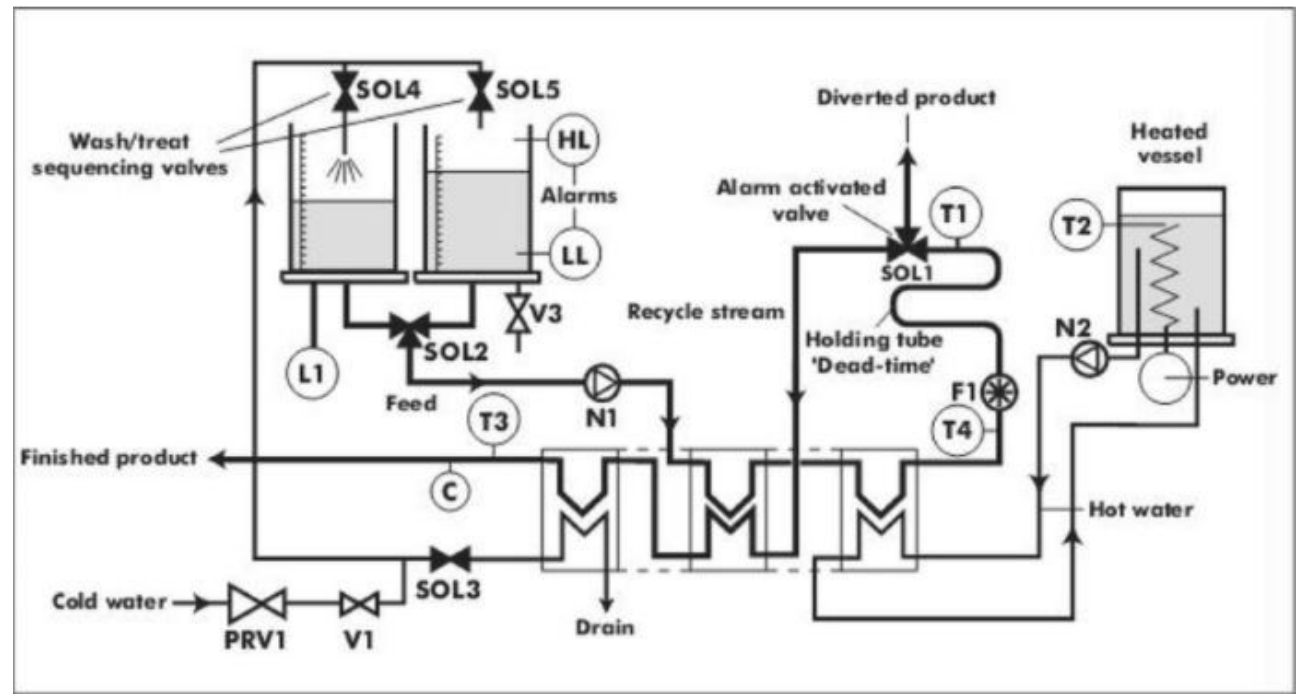

Gambar 2. Diagram Pasteurisasi Susu (Aadaleesan, dkk, 2008) 
Setelah fungsi alih diperoleh, maka langkah selanjutnya adalah merancang pengontrol PID yang paling sesuai terhadap proses tersebut. Proses perancangan penalaan PID dilakukan dengan menggunakan Metode Cohen Coon dan Ziegler Nichols. Setelah didapatkan parameter perancangannya, maka nilai penalaan tersebut dimasukkan ke dalam penalaan untuk PID di dalam perangkat keras PLC dan penalaan untuk MATLAB. Data dari MATLAB tersebut dikirimkan ke OPC dan selanjutnya PLC mengambil data tersebut dari OPC. Indikator capaiannya adalah program MATLAB dan Program PLC yang langsung bisa disimulasikan.

Data tersebut kemudian dikontrol dengan membandingkan tiga keadaan. Keadaan pertama, data tersebut dikontrol oleh PID yang ada pada PLC. Kemudian dari PLC, luaran tersebut dikirim ke OPC untuk kemudian dijadikan masukan pada sistem simulasi kontrol proses pasteurisasi di MATLAB. Tujuan penelitian menggunakan keadaan ini adalah untuk mengetahui kinerja pengontrol yang menggunakan PLC.

Sementara pada keadaan kedua, data yang sudah diterima oleh PLC selanjutnya dikirimkan ke OPC, lalu ke MATLAB. Pada MATLAB, digunakan pengontrol PID untuk mendapatkan sinyal kontrolnya. Sinyal kontrol tersebut kemudian dikirimkan kembali menggunakan OPC pada PLC. Setelah itu, sinyal tersebut dikirim kembali dari PLC ke OPC untuk kemudian disimulasikan pada MATLAB. Tujuan penelitian ini adalah untuk mengetahui kinerja pengontrol ketika pengontrolnya menggunakan MATLAB yang terintegrasi dengan OPC.

Sementara untuk keadaan ketiga, pengontrol hanya menggunakan MATLAB saja tanpa menggunakan OPC. Tujuannya adalah untuk mengetahui perbandingan kinerja pengontrol saat menggunakan antarmuka OPC dan yang tidak. Indikator capaiannya adalah simulasi data.

Analisis dilakukan terhadap rise time, maximum overshoot, dan settling time sistem, baik dari pengontrol yang berasal dari PLC dan pengontrol dari MATLAB. Indikator capaiannya adalah nilai-nilai parameter yang diperoleh dari sistem pasteurisasi menggunakan pengontrol yang berasal dari PLC yang terintegrasi dengan OPC, MATLAB, dan MATLAB yang terintegrasi menggunakan OPC.

\subsection{Jenis Pengontrol yang digunakan}

Alat penukar kalor adalah komponen penting pada sistem pasteurisasi. Pengontrolan menggunakan pengontrol PI dan PID biasa dilakukan pada alat penukar kalor. Salah satu yang sering digunakan adalah Kontrol Cascade PID-Fuzzy dan PI pada simulasi alat penukar kalor, di mana pengontrol ini mampu memberikan kinerja yang baik pada alat penukar kalor (Efendi, dkk, 2019). Namun, penelitian ini masih menggunakan simulasi MATLAB saja dan belum menggunakan PLC.

Salah satu parameter penting pada pengontrol PID adalah menentukan metode penalaan yang tepat sehingga perlu dilakukan penelitian terkait metode penalaan yang paling cocok digunakan untuk sistem pasteurisasi. Perbandingan kinerja 3 jenis penalaan PID, yaitu Ziegler Nichols, Chien, dan Cohen Coon menyimpulkan bahwa penalaan dengan kinerja terbaik adalah Metode Cohen Coon (Sen, dkk, 2015) (Srinivas, dkk, 2014). Namun, pengontrol PID ini diaplikasikan pada pengontrol posisi dan pada pengaturan level ketinggian air.

Di sisi lain, penalaan pengontrol menggunakan Metode Ziegler Nichols juga menghasilkan hasil yang baik sehingga bisa diaplikasikan pada sistem pasteurisasi susu. Pengontrolan suhu pada sistem pasteurisasi yang menggunakan pengontrol PID pada microcontroller menggunakan Metode Ziegler Nichols menunjukkan bahwa metode penalaan ini bisa digunakan baik pada pengontrol PID ataupun pengontrol PI (Dharmawan, dkk, 2019) (Singgih, 2017). Namun, penelitian-penelitian ini tidak melakukan perbandingan dengan metode penalaan lain. 
Proses pengontrolan sistem Pasteurisasi Susu ini menggunakan PLC dan MATLAB. Ada 3 konfigurasi yang digunakan, yaitu pengontrolan sistem menggunakan PLC yang terintegrasi dengan OPC, pengontrolan sistem dengan MATLAB saja, dan pengontrolan sistem menggunakan hasil integrasi OPC dan MATLAB. Perbandingan antara kinerja menggunakan MATLAB saja dan sistem yang menggunakan integrasi MATLAB dan OPC bertujuan untuk mengetahui seberapa besar pengaruh OPC pada sistem yang menggunakan PLC. Pengontrol terhubung dengan Fungsi Transfer Sistem Pasteurisasi yang ada pada MATLAB.

Ada 2 jenis penalaan PID yang diaplikasikan, baik pada pengontrol PID pada PLC maupun MATLAB, yaitu Penalaan Ziegler Nichols dan Cohen Coon. Kinerja yang ditinjau adalah waktu tunda, waktu puncak, overshoot dan steady state error.

Blok diagram ketiga konfigurasi dapat dilihat pada Gambar 3, 4 dan 5.

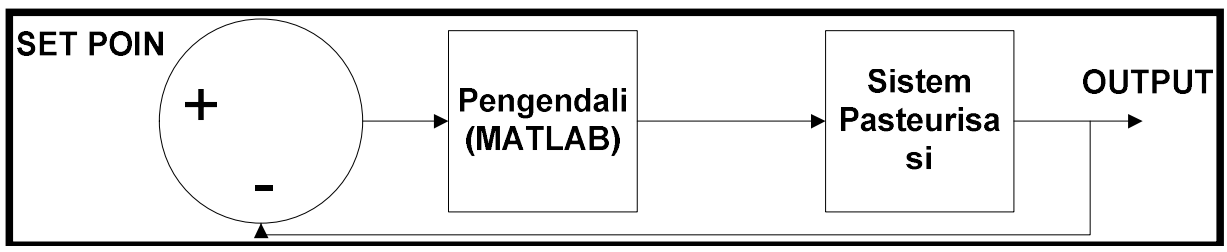

Gambar 3. Blok Diagram Pengontrol menggunakan MATLAB

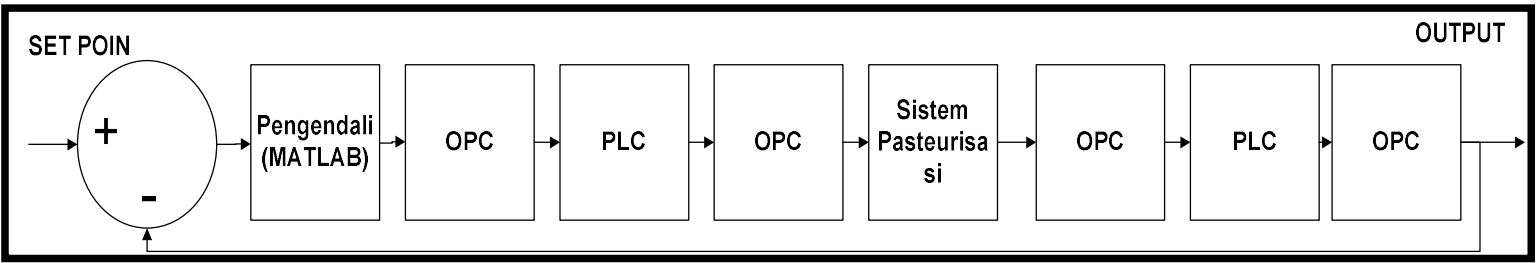

Gambar 4. Blok Diagram Pengontrol menggunakan MATLAB, OPC dan PLC

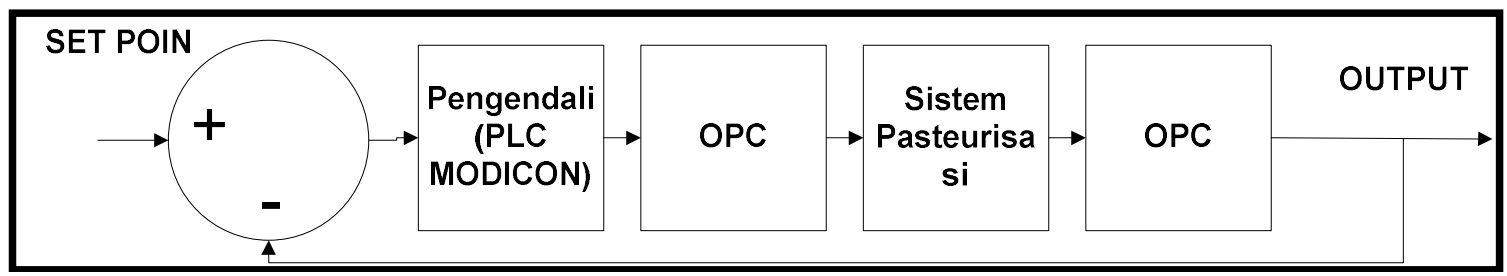

Gambar 5. Blok Diagram Pengontrol menggunakan PLC dan OPC

\subsection{Perancangan Pengontrol}

Pengontrol yang digunakan adalah pengontrol PID yang memiliki persamaan dalam domain waktu:

$$
u(t)=K_{p} e(t)+K_{p} T_{d} \frac{d e(t)}{d t}+\frac{K_{p}}{T_{i}} \int_{0}^{t} e(t) d t
$$

Sementara persamaan dalam domain Laplace adalah

$$
\frac{U(s)}{E(s)}=K_{p}\left(1+T_{d} s+\frac{1}{T_{i} s}\right)
$$


Nilai Kp adalah nilai penguat proporsional, sementara $\mathrm{Td}$ adalah waktu derivatif dan Ti adalah waktu integral. Dibutuhkan metode yang tepat untuk menentukan nilai $K_{p}, T_{d}$, dan $T_{i}$ agar sistem yang dikontrol memiliki kinerja terbaik. Metode penalaan yang dilakukan adalah Metode Ziegler Nichols dan Cohen-Coon. Penalaan PID menggunakan metode Ziegler Nichols memiliki dua metode, yaitu metode kurva reaksi dan metode osilasi. Pada penelitian ini digunakan metode kurva reaksi untuk mencari parameter $K_{p}, T_{i}$, dan $T_{d}$ dari pengontrol. Metode kurva reaksi dilakukan pada sistem loop terbuka pada proses pemanasan di plant pasteurisasi. Gambar kurva reaksi dapat dilihat pada Gambar 6.

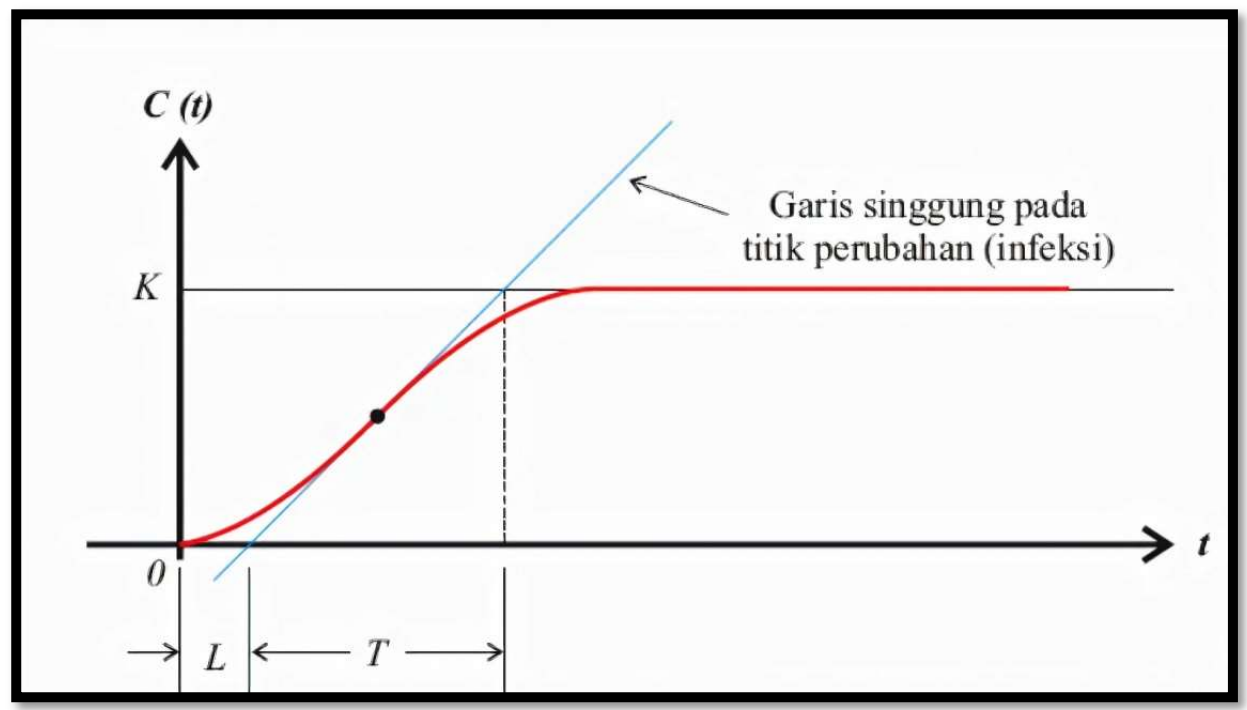

Gambar 1. Kurva Reaksi Penalaan

Ada dua konstanta yang dicari untuk digunakan dalam persamaan, konstanta L yang menyatakan waktu mati (dead time) L dan konstanta T yang menyatakan waktu tunda. Setelah kedua konstanta diperoleh, maka penalaan untuk pengontrol dilakukan berdasarkan tabel acuan.

Tabel untuk menentukan nilai Penalaan Pengontrol dapat dilihat pada Tabel 1 (Jamal, 2015).

Tabel 1. Penalaan untuk Metode Ziegler Nichols

\begin{tabular}{|c|c|c|c|}
\hline Tipe Pengontrol & $\boldsymbol{K}_{\boldsymbol{p}}$ & $\boldsymbol{T}_{\boldsymbol{i}}$ & $\boldsymbol{T}_{\boldsymbol{d}}$ \\
\hline $\mathrm{P}$ & $\mathrm{T} / \mathrm{L}$ & $\sim$ & 0 \\
\hline $\mathrm{PI}$ & $0,9 \mathrm{~T} / \mathrm{L}$ & $\mathrm{L} / 0,3$ & 0 \\
\hline $\mathrm{PID}$ & $1,2 \mathrm{~T} / \mathrm{L}$ & $2 \mathrm{~L}$ & $0,5 \mathrm{~L}$ \\
\hline
\end{tabular}

Metode penalaan lain yang digunakan adalah Metode Cohen Coon. Metode ini cocok digunakan untuk proses-proses yang memiliki waktu tunda yang relatif lama. Metode Cohen Coon didasari dengan model proses orde satu dengan waktu tunda atau FOPDT (First Order Plus Delay Time). Kelemahan dari penalaan empiris dengan Metode Cohen Coon adalah tidak tahan terhadap gangguan baik yang disebabkan dari dalam maupun luar sistem. Sedikit saja terdapat perubahan pada sistem maka sistem menjadi tidak stabil. 
Perbandingan Kinerja Pengontrol PID menggunakan Antarmuka OPC pada PLC dan MATLAB untuk Sistem Pasteurisasi Susu

Tabel 2 memperlihatkan besar parameter-parameter konstanta $K_{p_{r}} T_{i}$ dan $T_{d}$ berdasarkan penalaan dari Metode Cohen Coon, sesuai dengan bentuk pengontrol yang digunakan.

Tabel 2. Penalaan PID menggunakan Metode Cohen Coon

\begin{tabular}{|c|c|c|c|}
\hline Tipe Pengontrol & $\boldsymbol{K}_{\boldsymbol{p}}$ & $\boldsymbol{T}_{\boldsymbol{i}}$ & $\boldsymbol{T}_{\boldsymbol{D}}$ \\
\hline $\mathrm{P}$ & $\frac{1}{k} \frac{\tau}{\theta}\left[1+\frac{\theta}{3 \tau}\right]$ & & \\
\hline $\mathrm{PI}$ & $\frac{1}{k} \frac{\tau}{\theta}\left[0,9+\frac{\theta}{12 \tau}\right]$ & $\frac{\theta\left[30+3 \frac{\theta}{\tau}\right]}{9+20 \frac{\theta}{\tau}}$ & \\
\hline PID & $\frac{1}{k} \frac{\tau}{\theta}\left[\frac{16 \tau+3 \theta}{12 \tau}\right]$ & $\frac{\theta\left[32+6 \frac{\theta}{\tau}\right]}{13+8 \frac{\theta}{\tau}}$ & $\frac{4 \theta}{11+2 \frac{\theta}{\tau}}$ \\
\hline
\end{tabular}

Di mana $K$ adalah gain sistem, $t$ merupakan konstanta waktu sistem, dan $\theta$ adalah waktu tunda sistem.

Dengan menggunakan metode kurva reaksi tersebut, diperoleh nilai-nilai parameter $K_{p_{r}} T_{i}$ dan $T_{d}$ untuk Pengontrol dengan Penalaan Ziegler Nichols dan Cohen Coon. Hasilnya bisa dilihat pada Tabel 3.

Tabel 3. Nilai Penalaan Pengontrol

\begin{tabular}{|c|c|c|c|}
\hline Pengontrol & $\boldsymbol{K}_{\boldsymbol{p}}$ & $\boldsymbol{T}_{\boldsymbol{i}}$ & $\boldsymbol{T}_{\boldsymbol{d}}$ \\
\hline PID ZN & 5,67 & 58 & 14,5 \\
\hline PI ZN & 4,25 & 87 & 0 \\
\hline PID Cohen & 6,63 & 66,72 & 10,33 \\
\hline PI cohen & 4,33 & 67,58 & 0 \\
\hline
\end{tabular}

Nilai-nilai penalaan itu lalu dimasukkan sebagai nilai penalaan untuk pengontrol PI dan PID untuk semua jenis perangkat.

\subsection{Konfigurasi OPC}

OPC (Object Linked Embedded for Process Control) yang digunakan adalah OPC KEPServerEX versi 6. Hubungan komunikasi antara PLC dengan PC menggunakan kabel ethernet dengan protokol TCP/IP. Semua data dari PLC, baik digital maupun analog, dikirimkan ke OPC dan tipe datanya juga disesuaikan. Misalkan tipe data dari PLC adalah short integer, maka pengaturan data di OPC juga berupa short integer. PLC yang digunakan adalah PLC Modicon TM221. Konfigurasi OPC dapat dilihat pada Gambar 7.

Semua data OPC dapat dikirimkan ke MATLAB. MATLAB memiliki fitur OPC di bagian simulinknya. Setelah menentukan jenis OPC yang dihubungkan ke MATLAB, maka data yang ada di simulink bisa dikirimkan ke OPC lalu ke PLC. Data dari PLC juga bisa diterima oleh MATLAB. 


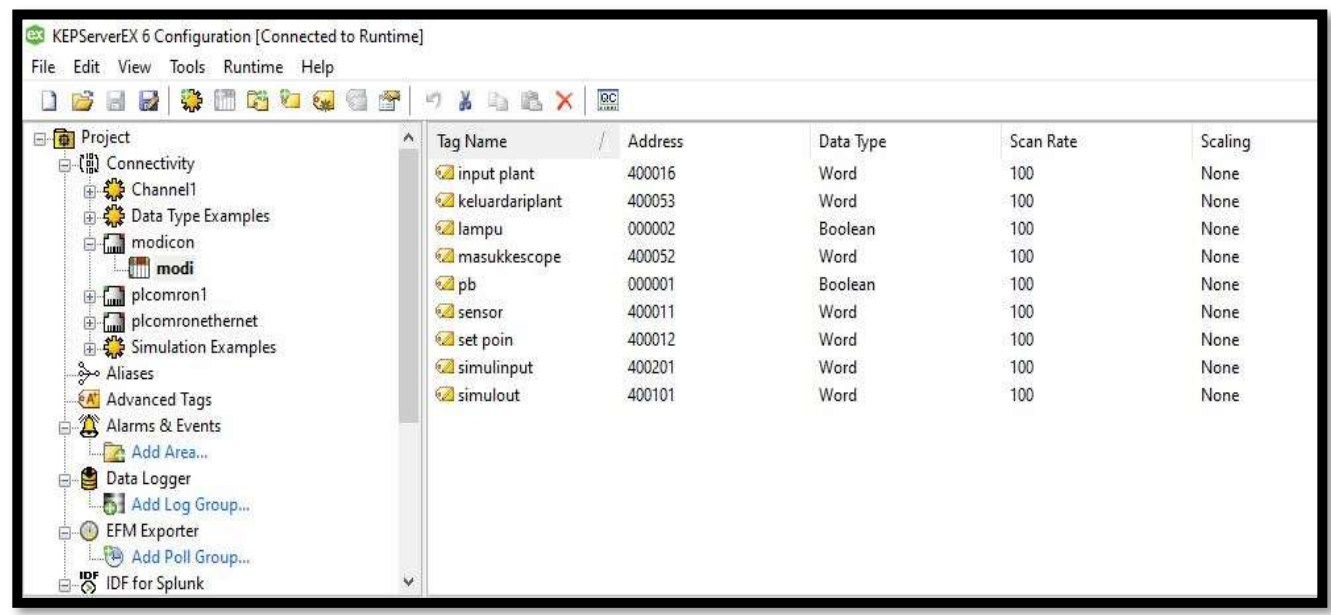

Gambar 2. OPC Quick Client

\section{ANALISIS DAN PEMBAHASAN}

\subsection{Pengontrol menggunakan OPC dan MATLAB}

Gambar 8 di bawah ini memperlihatkan respons transient sistem pasteurisasi pada pengontrol yang dirancang menggunakan MATLAB dan terintegrasi dengan OPC KEPServerEX. Sistem memiliki set point pada suhu $72{ }^{\circ} \mathrm{C}$. Dalam perbandingan ini terlihat bahwa secara umum pengontrol PID memiliki respon yang lebih baik untuk semua parameter yang dibandingkan. Namun, kinerja untuk pengontrol PI dan PID untuk kedua jenis penalaan tidak menunjukkan perbedaan yang signifikan. Di antara dua jenis penalaan yang dibandingkan, Penalaan Cohen Coon memiliki respon yang lebih baik di mana nilai maksimum overshoot-nya adalah 6,17 , time settling untuk error $5 \%$ adalah 539,5 detik, Mean Squared Error total adalah 154,67, serta nilai Mean Squared setelah sistem mencapai nilai setting $72{ }^{\circ} \mathrm{C}$ adalah sebesar 4,27. Namun, tidak ada pengontrol yang mampu memberikan nilai time settling untuk error $2 \%$ di bawah 1000 detik. Secara umum sistem dengan pengontrol ini kurang cocok diterapkan pada pasteurisasi susu yang memiliki toleransi temperatur yang tinggi untuk menjaga kualitas susu. Kinerja keseluruhan dapat dilihat pada Gambar 8.

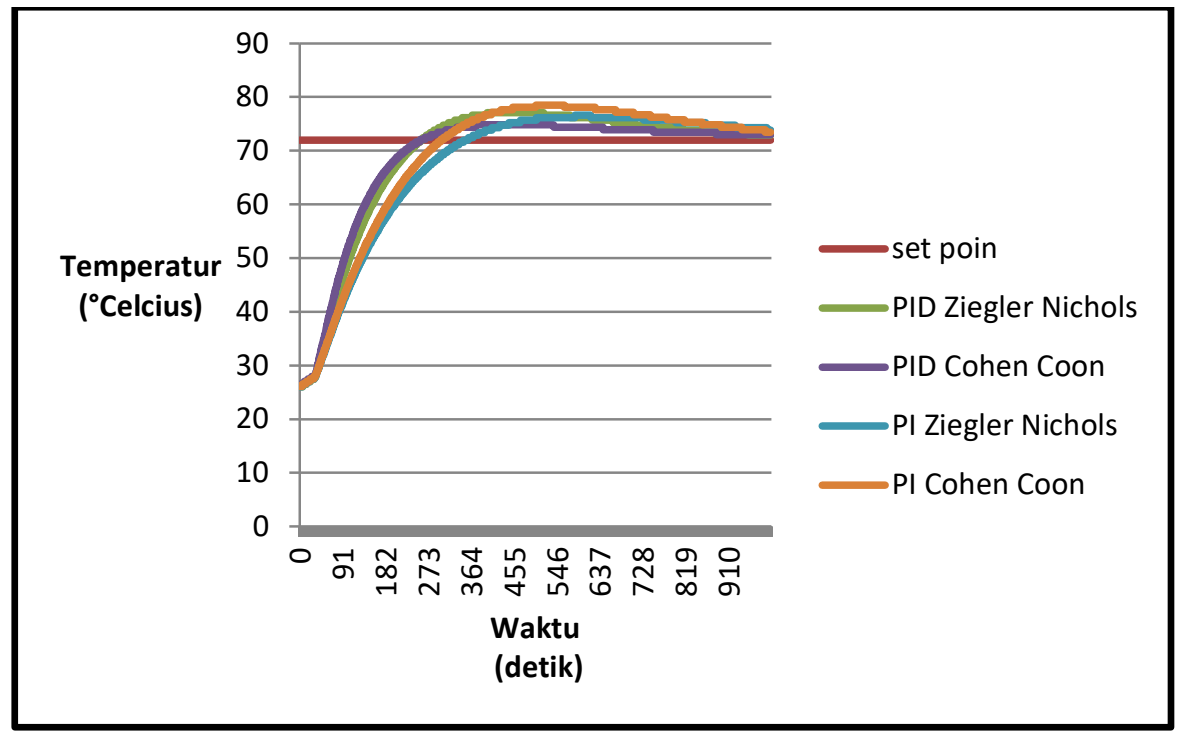

Gambar 3. Perbandingan Kinerja menggunakan MATLAB yang Terintegrasi dengan OPC 
Perbandingan Kinerja Pengontrol PID menggunakan Antarmuka OPC pada PLC dan MATLAB untuk Sistem Pasteurisasi Susu

Untuk nilai detailnya dapat dilihat pada Tabel 4. Secara umum dapat dilihat bahwa Pengontrol PID memiliki respons yang lebih bagus dibandingkan pengontrol PI. Namun, kekurangannya terlihat pada nilai time settling $2 \%$ yang tidak bisa mencapai nilai di bawah $100 \mathrm{~s}$.

Tabel 4. Kinerja Pengontrol pada MATLAB yang Terintegrasi OPC

\begin{tabular}{|c|c|c|c|c|c|c|c|c|}
\hline $\begin{array}{c}\text { Jenis } \\
\text { Pengontrol }\end{array}$ & Penalaan & $\begin{array}{c}\text { Time } \\
\text { rise (s) }\end{array}$ & $\begin{array}{c}\text { Time } \\
\text { Peak } \\
\text { (s) }\end{array}$ & $\begin{array}{c}\text { Over- } \\
\text { shoot } \\
\mathbf{( \% )}\end{array}$ & $\begin{array}{c}\text { Time } \\
\text { settling } \\
\mathbf{5 \%}\end{array}$ & $\begin{array}{c}\text { Time } \\
\text { Settling } \\
\mathbf{2 \%}\end{array}$ & MSE & $\begin{array}{c}\text { MSE } \\
\text { setelah } \\
\text { TR }\end{array}$ \\
\hline PID & ZN & $255,5 \mathrm{~s}$ & $458,2 \mathrm{~s}$ & 11 & $759 \mathrm{~s}$ & $\begin{array}{c}\text { Di atas } \\
1000 \mathrm{~s}\end{array}$ & 174,8 & 11,77 \\
\hline PID & CC & $261 \mathrm{~s}$ & $456,5 \mathrm{~s}$ & 6,17 & $539,5 \mathrm{~s}$ & $\begin{array}{c}\text { Di atas } \\
1000 \mathrm{~s}\end{array}$ & 154,67 & 4,27 \\
\hline PI & ZN & $353 \mathrm{~s}$ & $601 \mathrm{~s}$ & 10 & $925,5 \mathrm{~s}$ & $\begin{array}{c}\text { Di atas } \\
1000 \mathrm{~s}\end{array}$ & 210,75 & 11,52 \\
\hline PI & $\mathrm{CC}$ & $303 \mathrm{~s}$ & $531,5 \mathrm{~s}$ & 14,17 & $895 \mathrm{~s}$ & $\begin{array}{c}\text { Di atas } \\
1000 \mathrm{~s}\end{array}$ & 208,09 & 20,91 \\
\hline
\end{tabular}

\subsection{Pengontrol menggunakan MATLAB}

Pada kinerja sistem menggunakan pengontrol yang berasal dari MATLAB saja, terlihat bahwa kinerja sistem secara umum menunjukkan hasil yang tidak jauh berbeda dengan pengontrol yang menggunakan OPC dan MATLAB. Semua parameter menunjukkan hasil yang mirip. Hal ini berarti bahwa pengaruh waktu sampling dan waktu tunda pada penggunaan OPC untuk sistem pasteurisasi ini tidak menunjukkan perbedaan yang signifikan. Secara umum, terlihat bahwa tidak ada perbedaan signifikan di antara kinerja masing-masing pengontrol. Kinerja pengontrol dapat dilihat di Gambar 9.

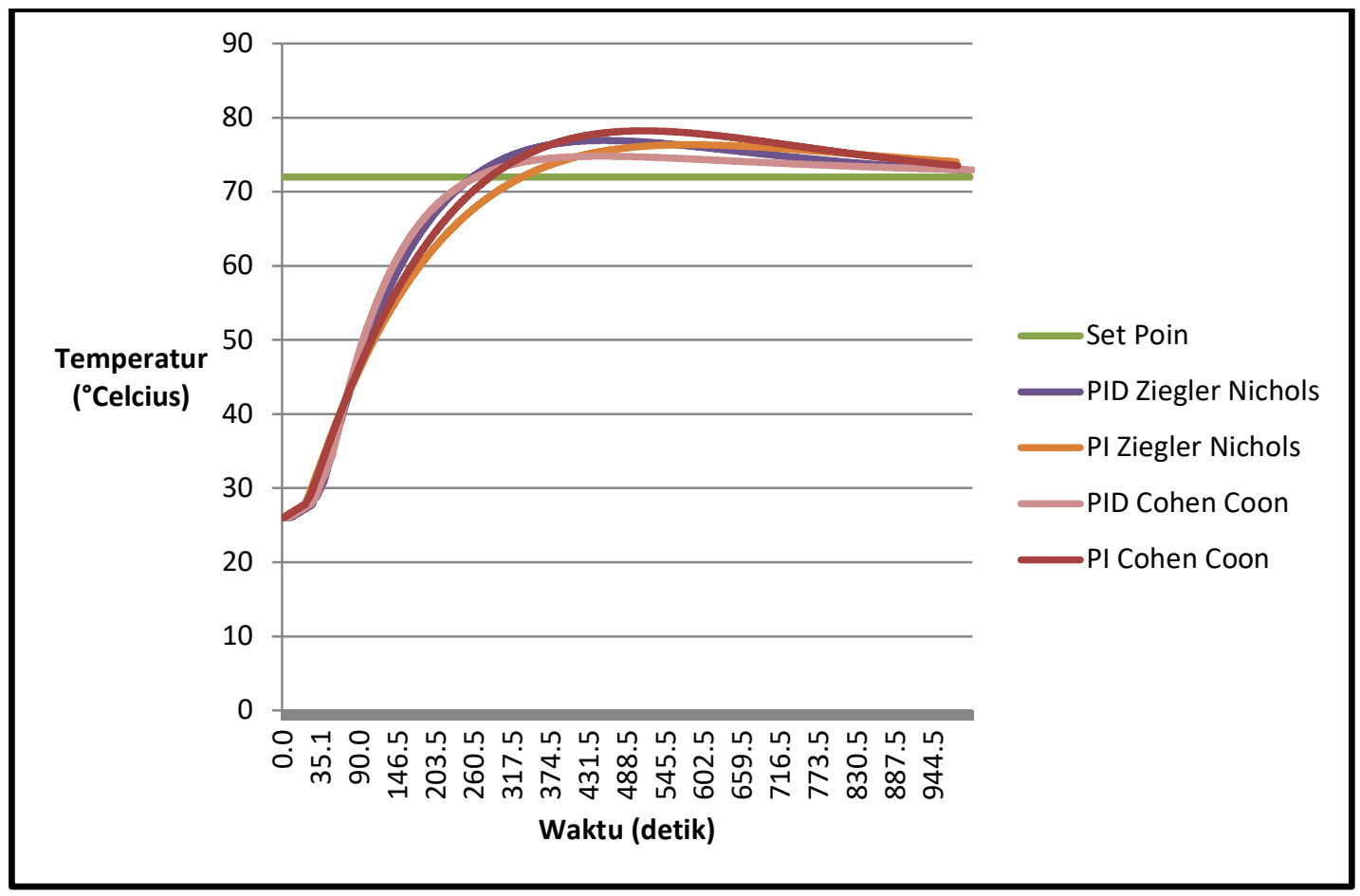

Gambar 4. Perbandingan Kinerja menggunakan MATLAB 
Tabel yang menunjukkan rincian kinerjanya dapat dilihat pada Tabel 5.

Tabel 5. Kinerja Pengontrol menggunakan MATLAB

\begin{tabular}{|c|c|c|c|c|c|c|c|c|}
\hline $\begin{array}{c}\text { Jenis } \\
\text { Pengontrol }\end{array}$ & Penalaan & $\begin{array}{c}\text { Time } \\
\text { rise } \\
\mathbf{( s )}\end{array}$ & $\begin{array}{c}\text { Time } \\
\text { Peak } \\
\mathbf{( s )}\end{array}$ & $\begin{array}{c}\text { Over- } \\
\text { shoot } \\
\mathbf{( \% )}\end{array}$ & $\begin{array}{c}\text { Time } \\
\text { settling } \\
\mathbf{5 \%} \mathbf{( s )}\end{array}$ & $\begin{array}{c}\text { Time } \\
\text { Settling } \\
\mathbf{2 \%}(\mathbf{s})\end{array}$ & MSE & $\begin{array}{c}\text { MSE } \\
\text { setelah } \\
\text { TR }\end{array}$ \\
\hline PID & ZN & $255 \mathrm{~s}$ & $454,5 \mathrm{~s}$ & 11,34 & $778,24 \mathrm{~s}$ & $\begin{array}{c}\text { Di atas } \\
1000 \mathrm{~s}\end{array}$ & 209,58 & 11,3 \\
\hline PID & $\mathrm{CC}$ & $261,5 \mathrm{~s}$ & $447,24 \mathrm{~s}$ & 6,07 & $535,24 \mathrm{~s}$ & $\begin{array}{c}\mathrm{Di} \text { atas } \\
1000 \mathrm{~s}\end{array}$ & 196,17 & 4,65 \\
\hline PI & $\mathrm{ZN}$ & $353,5 \mathrm{~s}$ & $602,76 \mathrm{~s}$ & 9,43 & $916,24 \mathrm{~s}$ & $\begin{array}{c}\text { Di atas } \\
1000 \mathrm{~s}\end{array}$ & 214,19 & 11,54 \\
\hline PI & $\mathrm{CC}$ & $303,5 \mathrm{~s}$ & $531,75 \mathrm{~s}$ & 13,51 & $889 \mathrm{~s}$ & $\begin{array}{c}\text { Di atas } \\
1000 \mathrm{~s}\end{array}$ & 215,49 & 19,93 \\
\hline
\end{tabular}

Pada tabel terlihat bahwa Kinerja Pengontrol PID lebih baik dibandingkan pengontrol PI. Namun, time settling $2 \%$ tidak ada yang berada di bawah $1000 \mathrm{~s}$.

\subsection{Pengontrol menggunakan PLC}

Pada Gambar 10, dapat terlihat bahwa jika dibandingkan dengan pengontrol yang menggunakan MATLAB, terdapat perbedaan signifikan di antara pengontrol PI dan PID. Sistem pengontrol yang terdapat pada MATLAB lebih bersifat robust, tetapi kinerja pengontrol PID pada PLC menunjukkan hasil yang jauh lebih baik. Pengontrol PID dengan menggunakan Cohen Coon menunjukkan kinerja terbaik dibandingkan dengan seluruh pengontrol yang ada, baik menggunakan PLC, MATLAB dengan OPC ataupun MATLAB saja. Nilai overshoot-nya hanya 3,63\%, terendah dari semua pengontrol yang ada. Nilai time settling error $5 \%$ menunjukkan nilai 192,76 s. Sementara untuk error $2 \%$ adalah 357,24 s. Nilai MSE setelah mencapai time rise adalah 0,356. Kinerja keseluruhan sistem dapat dilihat pada Gambar 10.

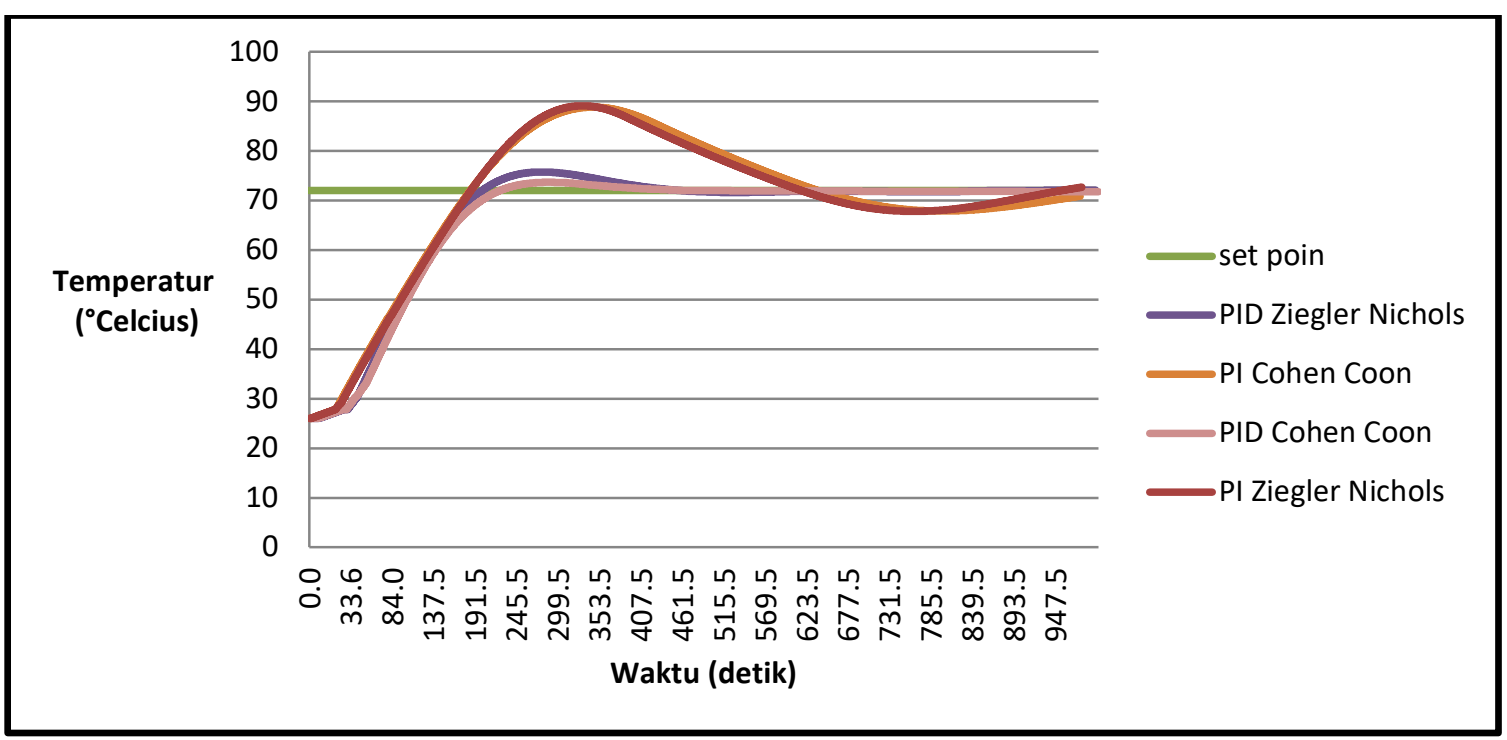

Gambar 5. Perbandingan Kinerja menggunakan PLC 
Perbandingan Kinerja Pengontrol PID menggunakan Antarmuka OPC pada PLC dan MATLAB untuk Sistem Pasteurisasi Susu

Tabel rincian kinerjanya dapat dilihat pada Tabel 6.

Tabel 6. Kinerja Pengontrol PLC

\begin{tabular}{|c|c|c|c|c|c|c|c|c|}
\hline $\begin{array}{c}\text { Jenis } \\
\text { Pengontrol }\end{array}$ & Penalaan & $\begin{array}{c}\text { Time } \\
\text { rise (s) }\end{array}$ & $\begin{array}{c}\text { Time } \\
\text { Peak } \\
(\mathbf{s})\end{array}$ & $\begin{array}{c}\text { Over- } \\
\text { shoot } \\
\mathbf{( \% )}\end{array}$ & $\begin{array}{c}\text { Time } \\
\text { settling } \\
\mathbf{5 \%}(\mathbf{s})\end{array}$ & $\begin{array}{c}\text { Time } \\
\text { Settling } \\
\mathbf{2} \% \mathbf{( s )}\end{array}$ & MSE & $\begin{array}{c}\text { MSE } \\
\text { setelah } \\
\text { TR }\end{array}$ \\
\hline PID & ZN & $201 \mathrm{~s}$ & $279,5 \mathrm{~s}$ & 8,18 & $352,76 \mathrm{~s}$ & $404,5 \mathrm{~s}$ & 198,9 & 1,969 \\
\hline PID & CC & $220,5 \mathrm{~s}$ & $281,76 \mathrm{~s}$ & 3,63 & $192,76 \mathrm{~s}$ & $357,24 \mathrm{~s}$ & 202,21 & 0,356 \\
\hline PI & ZN & $205,8 \mathrm{~s}$ & $365,76 \mathrm{~s}$ & 36,61 & $944,5 \mathrm{~s}$ & $\begin{array}{c}\text { Di atas } \\
1000 \mathrm{~s}\end{array}$ & 236,21 & 74,86 \\
\hline PI & CC & $204,5 \mathrm{~s}$ & $350,25 \mathrm{~s}$ & 37,21 & $890,25 \mathrm{~s}$ & $\begin{array}{c}\text { Di atas } \\
1000 \mathrm{~s}\end{array}$ & 236,27 & 70,45 \\
\hline
\end{tabular}

Dari Tabel 6 dapat terlihat bahwa kinerja pengontrol PID Cohen Coon memiliki respons terbaik. Sementara sistem pasteurisasi yang menggunakan pengontrol PI tidak bisa menghasilkan nilai time settling di bawah 1000 s. Nilai MSE pada pengontrol PID juga jauh lebih baik dibandingkan dengan nilai MSE pada pengontrol PI.

\section{KESIMPULAN}

Dari penelitian ini dapat disimpulkan bahwa pengontrol yang sama dan menggunakan metode penalaan yang sama dapat menghasilkan kinerja yang berbeda-beda. Pengontrol yang digunakan pada MATLAB dan pada MATLAB yang diintegrasikan dengan OPC menghasilkan respons yang hampir sama. Hal ini berarti bahwa perbedaan waktu sampling dan waktu tunda tidak terlalu berpengaruh pada sistem yang memiliki respons yang lambat sehingga penggunaan OPC sebagai antarmuka pada sistem ini tidak mengurangi kinerja pengontrol. Sistem ini cukup aman untuk dikontrol dengan menggunakan pengontrol lain. Pengontrol yang menggunakan PLC sebagai piranti pengontrolnya memiliki rentang kinerja yang cukup luas. Kinerja terbaik memang ditunjukkan oleh pengontrol PID Cohen Coon. Namun, kinerja terburuk ditunjukkan oleh pengontrol PI Ziegler Nichols. Hal ini menunjukkan bahwa dalam perancangan pengontrol menggunakan PLC harus dilakukan penalaan dengan tingkat kepresisian yang lebih baik karena potensi ketidakstabilan cukup besar. Pengontrol PID Cohen Coon cocok diterapkan pada sistem pasteurisasi susu karena menghasilkan overshoot yang kecil sehingga proses pasteurisasi menggunakan pengontrol ini tidak akan merusak kualitas susu. Pengontrol ini juga mampu mempercepat respons.

\section{UCAPAN TERIMA KASIH}

Terima kasih kepada Direktorat Jenderal Pendidikan Tinggi Kementerian Pendidikan dan Kebudayaan Republik Indonesia yang telah membiayai penelitian ini melalui hibah PDP (Penelitian Dosen Pemula) tahun pelaksanaan 2020. 


\section{DAFTAR RUJUKAN}

Aadaleesan, P., Miglan, N., Sharma, R., \& Saha, P. (2008). Nonlinear System Identification using Wiener type Laguerre-Wavelet Network Model. Chemical Engineering Science, 63(15), 3932-3941. https://doi.org/10.1016/j.ces.2008.04.043

Alamirew, T., Balaji, V., \& Gabbeye, N. (2017). Comparison of PID Controller with Model Predictive Controller for Milk Pasteurization Process. Bulletin of Electrical Engineering and Informatics, 6(1), 24-35. https://doi.org/10.11591/eei.v6i1.575

Cao, J., Ye, Q., \& Li, P. (2015). Resistance Furnace Temperature Control System Based on OPC and MATLAB. Measurement and Control (United Kingdom), 48(2), 60-64. https://doi.org/10.1177/0020294015569257

Dharmawan, A., Marthen, B., Adam, F., Sari, I. P., \& Maulana, R. (2019). Sistem Kontrol Proporsional-Integral Pada Proses Pasteurisasi Susu. Transmisi, 21(1), 15-18. https://doi.org/10.14710/transmisi.21.1.15-18

Efendi, Y., Mardiyah, N. A., \& Has, Z. (2019). Desain dan Verifikasi Kontrol Cascade Pengendali Suhu Berbasis Fuzzy-PID dan PI pada Heat Exchanger. Seminar FORTEI, (pp. 107113)

Jamal, Z. (2015). Implementasi Kendali PID Penalaan Ziegler-Nichols Menggunakan Mikrokontroler. Jurnal Informatika, 15(1), 81-88

Kafuko, M., \& Wanyama, T. (2015). Integrated Hands-on and Remote PID Tuning Laboratory. Proc. 2015 Canadian Engineering Education Association (CEEA15) Conf., (pp. 1-5)

Łšmieja, M., Bogdański, P., \& Czerwiński, K. (2018). Modelling of Pasteurization Process Line in Dairy Industry in Context of Process Control. AIP Conference Proceedings, (pp. 020074.1-020074.6). https://doi.org/10.1063/1.5066536

Pranowo, I. D., Bagastama, Y. B. T., \& Wibisono, T. A. F. (2020). Communication between PLC Different Vendors Using OPC Server Improved with Application Device. Telkomnika (Telecommunication Computing, Electronics, and Control), 18(3), 1491-1498. https://doi.org/10.12928/TELKOMNIKA.v18i3.14757

Sartika, E. M., Sarjono, T. R., \& Saputra, D. D. (2019). Prediction of PID control model on PLC. Telkomnika (Telecommunication Computing Electronics and Control), 1入1), 529-536. https://doi.org/10.12928/TELKOMNIKA.v17i1.11589

Sen, R., Pati, C., Dutta, S., \& Sen, R. (2015). Comparison Between Three Tuning Methods of PID Control for High Precision Positioning Stage. Mapan - Journal of Metrology Society of India, 30(1), 65-70. https://doi.org/10.1007/s12647-014-0123-z

Singgih, H. (2017). Optimization of PID Controler In Temperature Control System Processes 
Perbandingan Kinerja Pengontrol PID menggunakan Antarmuka OPC pada PLC dan MATLAB untuk Sistem Pasteurisasi Susu

Pasteurization of Milk. American Journal of Engineering Research, 6(9), 175-187. www.ajer.org

Srinivas, P., Lakshmi, K., \& Kumar, V. (2014). A Comparison of PID Controller Tuning Methods for Three Tank Level Process. International Journal of Advance Research in Electrical, Electronic and Instrumentation Engineering, 3(1), 6810-6820.

Suthar, J., Patel, S., Patel, N., \& Singh, R. (2015). Implementation of Self Tuning Pid Controller in Pasteurizer Machine for Food and Beverage Industry Using Siemens S7-300 PLC. International Journal of Advance Engineering and Research Development, 2(02), 316322. https://doi.org/10.21090/ijaerd.020247

Valarezo, M., Salinas, E., Romero, J., \& Jara, D. (2016). Application of an OPC System for Mineral Extraction in a Copper Mine Laboratory Scale. International Journal of Engineering and Advanced Techmology (IJEAT), 5(6), 9-12.

Wanyama, T., \& Singh, I. (2013). A Training Demonstration for Experiential Learning in OPC Based Process Automation Data Access. Proc. 2013 Canadian Engineering Education Association (CEEA13) Conf., (pp. 17-20)

Watts, S. (2016). A Mini Review on Technique of Milk Pasteurization. Journal of Pharmacognosy and Phytochemistry (JPP), 5(5), 99-101. http://www.phytojournal.com/archives/2016/vol5issue5/PartB/5-4-36-907.pdf 